\title{
Universal Basic Income as a Policy Response to COVID-19 and Precarious Employment: Potential Impacts on Rehabilitation and Return-to-Work
}

\author{
Christian Ståhl ${ }^{1,2}$ (1) Ellen MacEachen ${ }^{3}([)$
}

Published online: 20 August 2020

๑) Springer Science+Business Media, LLC, part of Springer Nature 2020

The COVID-19 pandemic has opened up thinking about how our social security programs, including workers' compensation, function and whether they are able to provide adequate support to people in the context of today's difficult health and work conditions [1]. One policy option that has persistently emerged, across countries and over recent decades, is that of Universal Basic Income (UBI). In this editorial, we discuss UBI as a possible solution for some consequences of the COVID-19 pandemic and also as a long-term solution to our changing economies that increasingly include precarious employment and income insecurity.

At present, with COVID-19, we have a dramatic situation of un- and under-employment for which there are no ready policy remedies. Instead, we have seen emergency limited-term hand-outs, such as the payout of $\$ 1200$ to all US citizens with a gross income less than $\$ 75,000-\$ 150,000$ in April 2020, ${ }^{1}$ and the Canadian Emergency Response Benefit that provided $\$ 500$ per week to Canadian citizens who have stopped working due to COVID-19, for up to 24 weeks. $^{2}$ Although not universal, this Canadian benefit extended to groups who had previously not been recognized

\footnotetext{
${ }^{1} \mathrm{https}: / / \mathrm{www}$. irs.gov/coronavirus/economic-impact-payment-infor mation-center (retrieved July 3, 2020).

${ }^{2}$ https://www.canada.ca/en/services/benefits/ei/cerb-application.html (retrieved July 3, 2020)
}

Christian Ståhl

christian.stahl@liu.se

Ellen MacEachen

ellen.maceachen@uwaterloo.ca

1 Department of Behavioural Sciences and Learning, Division of Education and Sociology, Linköping University, Linköping, Sweden

2 HELIX Competence Centre, Linköping University, Linköping, Sweden

3 School of Public Health and Health Systems, University of Waterloo, Waterloo, Canada as possible recipients of unemployment benefits, including self-employed, gig workers and part-time workers. Similar cash handouts were issued in Japan, while other countries had targeted cash transfers to vulnerable groups. ${ }^{3}$

In what follows, we outline what UBI entails and how it relates to rehabilitation and RTW.

\section{What is Universal Basic Income?}

A common definition of UBI is "an income paid by a political community to all its members on an individual basis, without means test or work requirement" [2, p. 8]. This definition includes two central characteristics of the UBI idea: (1) that it needs to be universal, i.e., independent of a person's level of income, employment status, work ability or other indicators commonly used to determine eligibility for social security benefits, and (2) that it is unconditional, i.e., that there are no demands on the person receiving it, such as the requirement to participate in employment programs or to actively seek employment.

The idea of a UBI has been promoted by people across the political spectrum, as a way of replacing dysfunctional welfare bureaucracies with simpler models that replace complex state bureaucracies with a more efficient, singular model (popular with the political right), or by providing support to individuals without qualifying conditions (popular with the political left) [3]. There have been several experiments and pilots (e.g. in Ontario and Finland [4, 5]), and new ones are under way or are being debated in several countries (e.g., in the Netherlands and Scotland [6]).

Despite features of UBI that attract those on the right and the left of political spectrums, suspicion to UBI remains. A key critique has been that a minimum income would

\footnotetext{
3 https://www.imf.org/en/Topics/imf-and-covid19/Policy-Responsesto-COVID-19 (retrieved July 3, 2020).
} 
decrease people's incentive to work. However, pilots of UBI have shown no or limited decreases in work participation [7-9]. Results from an experiment in Manitoba, Canada, in the 1970s demonstrated how such effects were negligiblethose who withdrew from work did this in order to engage in education or care work, or because they had disabilities or uneven employment opportunities. The Manitoba experiment also showed reduced health care use [9]. Results from a recent two-year experiment carried out in Finland also showed overall positive results. In this experiment, a number of people were provided with unemployment benefits with no obligation to seek employment and no reduction in their benefit if they found work. This experiment showed higher life satisfaction, better mental health, and increased trust in authorities compared to the control group. As well, there were no adverse effects on employment outcomes [5].

Some have argued that a decrease in employment, should it occur with UBI, would not necessarily be a negative outcome. This is because full employment is an uncertain ideal in a context where automation has caused many jobs to disappear and where unemployment rates are generally higher today than in previous decades [10]. From this perspective, and in the context of the unstable economies caused by COVID-19, UBI does not undermine paid labor. Rather, it helps people attain a level of autonomy by providing them with financial stability and decreases their reliance on having a job in order to have sufficient income to pay for basic needs such as food and housing.

A further benefit of UBI is that it can potentially empower a worker to refuse bad or unsafe work. In such instances, UBI could facilitate people's efforts to seek different employment or start a new career.

UBI may actually lead to increased labor participation by alleviating the many different "policy traps" that limit people's ability to participate in the labor force. These include the poverty and unemployment traps of being caught in social assistance or unemployment benefits, because receiving an income from work decreases the benefit award or amount. Another is the employment trap, when being caught in low-wage jobs in order to survive makes it impossible to invest time or income into things such as child care and education that might, in the long run, prove beneficial to employment [11]. To this, we add a "disability trap", where income support depends on individuals' ability to prove their inability to work due to injury or illness. This takes time away from actual rehabilitation and may disincentivize people from attempting to overcome their disability.

Ultimately, UBI provides a perspective of human motivation that stands in contrast to most social security systems, which begin with the assumption that people are unwilling to work. In contrast, UBI presumes that people in general are not content with idleness and would like to work to realize their potential, if given the chance. UBI may also improve peoples' health by limiting the number of intrusive contacts with authorities and reducing financial insecurity [12].

\section{An Emergency UBI?}

A temporary variety of UBI has become a popular suggestion during the COVID-19 pandemic as a way of combatting challenges during a specific time of crisis. In an online conversation about emergency UBI during COVID-19 in the United States, philosopher Karl Widerquist argues that there are four main reasons for such a policy:

1. it serves as a cushion for people who are un- or underemployed during the crisis;

2. it also serves as a cushion for people who need to keep working - the essential workers-who often have very low wages and could benefit from a bonus that recognizes their contribution to society;

3. it serves as a stimulus for the economy as a whole and limits multiplier effects; and

4. it is simpler than other policies, as it involves fewer transaction costs and less bureaucracy (such as delays due to determining eligibility). ${ }^{4}$

An emergency UBI is also, according to Widerquist, a better experiment to learn from than the previous pilot projects, which were all limited in scale either by singling out specific groups such as the unemployed, or focusing on a limited geographic area. An emergency UBI would allow for observation of effects on the community level, albeit under extraordinary conditions.

Since some of the policy measures taken during the pandemic have taken forms which are approaching UBI, we are in an unprecedented position to study what such policies mean for peoples' lives, with regard to economic, social, health and employment-related effects. It would be interesting to learn the degree to which the basic financial security of a guaranteed income impacts individuals' views on work, and how such a policy helps workers to survive while working in precarious jobs or gig work.

COVID-19 has brought previously less visible problems into view-such as inequalities in the labor market with regard to income and working conditions, and the fragility of the economy which is apparently not equipped to deal with extreme external shocks. A flexible labor market, while advantageous to employers, poses a problem for workers who have to survive through employment in precarious or self-employed gig jobs where social security systems are not designed for such non-standard employment contracts. While UBI provides an option for the widespread unemployment that has occurred with the COVID-19 pandemic,

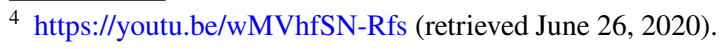


experiences from the crisis also provoke the question of whether current social security systems are sufficient for security in a flexible economy.

\section{Potential Impacts on Rehabilitation and Return-to-Work}

A permanent UBI policy could have a positive impact on rehabilitation and return-to-work (RTW) structures but may have different implications depending on how it is implemented. If UBI were to replace all existing support structures, the level of the UBI could be significantly lower than awards provided by workers' compensation or other incomebased social insurance systems. This would be a setback for some populations, such as those with work disability. UBI could, however, be implemented as a basic platform upon which workers' compensation or social insurance benefits would be added [13]. Assessments of eligibility would remain in these additional systems, including the iatrogenic risks related to such administrative procedures [14]. In such a scenario, UBI would be able to manage the poverty, employment and unemployment traps, but not the disability trap. Overall, a positive effect of UBI would be that the risk of poverty would diminish.

The main advantage of UBI is that it offers financial stability to individuals that is never uncertain or questioned. This would likely most benefit disadvantaged workers, such as people working in precarious jobs or in the gig economy, as UBI would reduce the stress of irregular income (e.g. zero-hours contracts, varying gig income) or losing one's income. It could also serve as a safety net for those who do not qualify for other benefits due to weak employment status, without stigmatizing the recipients. Further, in the context of COVID-19, UBI would support the temporary workers who see their livelihood vanishing with the crumbling economy.

UBI differs from most work disability prevention policies in its approach to work, where the current systems generally subscribe to an activation paradigm where work is seen as normatively desirable [15]. Such activation policies tend to use negative approaches, where restricting access to benefits is a core approach and where it is not uncommon to entirely disregard a person's educational background in determining eligibility or when assessing work ability [16]. UBI takes a different, more positive, approach to peoples' motivation to work.

\section{Conclusions}

UBI is uncharted territory. The best evidence that we have of its effects comes from limited pilots and experiments, where the generalizability to whole communities is limited. For its application to rehabilitation and RTW during the
COVID-19 era, the effects are largely unexplored, including how UBI would affect the dynamics between stakeholders involved in RTW processes. These are all areas for which occupational rehabilitation research is needed. However, it might be argued that introducing UBI, while relying partly on evidence, is ultimately an ideological or pragmatic policy choice based on beliefs about obligations regarding social reciprocity in society, similar to how choices to introduce social insurance and workers' compensation were made over a century ago. The COVID-19 pandemic has led to the idea of UBI taking root in the imagination of some policy-makers, although the effects of a permanent UBI remain to be understood, especially in relation to translating it into practice for work disability in comprehensive and cause-based systems.

\section{References}

1. Shaw WS, et al. Opening the workplace after COVID-19: what lessons can be learned from return-to-work research? J Occup Rehabil. 2020. https://doi.org/10.1007/s10926-020-09908-9.

2. Van Parijs P. Basic income: a simple and powerful idea for the twenty-first century. Politics Soci. 2004;32(1):7-39. https://doi. org/10.1177/0032329203261095.

3. De Wispelaere J, Stirton L. The many faces of universal basic income. Politics Q. 2004;75(3):266-274.

4. Ferdosi M, et al. Southern Ontario's basic income experience. In: Hamilton roundtable for poverty reduction. Hamilton: McMaster University; 2020.

5. Kangas O, et al. Evaluation of the Finnish basic income experiment. In: Reports and memorandums of the ministry of social affairs and health. Helsinki: The Ministry of Social Affairs and Health; 2020.

6. Gentilini U, et al. Exploring universal basic income: a guide to navigating concepts, evidence, and practices. Washington, DC: The World Bank; 2020.

7. Bregman R. Utopia for realists and how we can get there. London: Bloomsbury; 2017.

8. Standing G. Basic income: and how we can make it happen. London: Pelican; 2017.

9. Calnitsky D, Latner JP. Basic income in a small town: understanding the elusive effects on work. Soc Probl. 2017;64(3):373-397. https://doi.org/10.1093/socpro/spw040.

10. OECD. Putting faces to the jobs at risk of automation. In: Policy brief on the future of work. Paris: OECD Publishing; 2018.

11. Van Parijs P, Vanderborght Y. Basic income: a radical proposal for a free society and a sane economy. Cambridge: Harvard University Press; 2017.

12. Fagerlind Ståhl A-C. Health-promoting potentials of basic income: an analysis of the psychosocial environment in work and welfare. Sheffield: Centre for Welfare Reform; 2019.

13. Birnbaum S. Basic income reconsidered. Social justice, liberalism, and the demands of equality. New York: Palgrave Macmillan; 2012.

14. Kilgour E, et al. Interactions between injured workers and insurers in workers' compensation systems: a systematic review of qualitative research literature. J Occup Rehabil. 2015;25(1):160-181. https://doi.org/10.1007/s10926-014-9513-x.

15. Martin JP. Activation and active labour market policies in OECD countries: stylized facts and evidence on their effectiveness. Bonn: IZA Institute of Labor Economics; 2014. 
16. Ståhl C, Seing I. Reforming activation in swedish work disability policy. In: MacEachen E, editor. The science and politics of work disability prevention. Oxford: Routledge; 2018.
Publisher's Note Springer Nature remains neutral with regard to jurisdictional claims in published maps and institutional affiliations. 